\title{
Efeitos da Endogamia sobre Características de Reprodução, Crescimento e Valores Genéticos Aditivos de Bovinos da Raça Pardo-Suíça ${ }^{1}$
}

\author{
Alencariano José da Silva Falcão², Raimundo Martins Filho ${ }^{3}$, Cláudio de Ulhôa Magnabosco 4 , \\ Riccardo Bozzi ${ }^{5}$, Francisco de Assis Melo Lima ${ }^{3}$
}

\begin{abstract}
RESUMO - Avaliaram-se os efeitos da endogamia sobre o intervalo de partos (IDP), peso ao nascer (PN), peso à desmama (PD) e os valores genéticos direto e materno para o PN, a partir de dados coletados no período de 1946 a 1993, do rebanho Pardo Suíço "puro de origem”, pertencente à Universidade Federal do Ceará. Os valores genéticos foram preditos por soluções de equações de modelos mistos, assumindo um modelo animal. O coeficiente de endogamia $(\mathrm{F})$ foi calculado pelo método proposto por WRIGHT, utilizando-se o aplicativo MTDFREML. A matriz de parentesco incluiu 1209 animais, cujos valores médio e máximo de $\mathrm{F}$ foram 12,50 e 38,30\%, respectivamente. De um modo geral, aumentos nos níveis de F foram acompanhados de redução no mérito genético individual para o PN. O efeito genético direto para PN respondeu por $47 \%$ da variância total e o efeito materno, por 40\%. Para IDP foram significativos os efeitos de ano e ordem de parição e pai da vaca, sendo estimado acréscimo de 1,4 dias para cada 1\% de aumento na endogamia direta. Para PN foram significativos os efeitos de ano de nascimento dentro de período, sexo, categoria de idade da vaca ao parto e a endogamia linear e quadrática direta. Para PD foi significativo o efeito de ano de nascimento e a estimativa do coeficiente de regressão do PD sobre a endogamia materna foi $-0,51 \pm 0,14 \mathrm{~kg}$.
\end{abstract}

Palavras-chave: endogamia, intervalo de parto, Pardo Suíço, pesos, valor genético

\section{Effects of Inbreeding on Reproductive and Growth Traits, and Breeding Values in a Closed Brown Swiss Herd}

\begin{abstract}
Inbreeding effects on calving interval (CI), birth weight (BW), weaning weight (WW) and on the direct and maternal breeding values for BW were evaluated in a purebred Brown Swiss herd raised in northeast Brazil. Data were collected from 1946 to 1993. Inbreeding coefficients (F) were estimated according to Wright method using the MTDFREML package. Breeding values were predicted by a BLUP animal model that included fixed effects of sex, month and year of birth, parity of dam and direct and maternal inbreeding as covariate. The relationship matrix included 1209 animals and the average and maximum inbreeding were $12.50 \%$ and $38.30 \%$ respectively. In general, increases in inbreeding levels were followed by reductions on direct breeding value for BW. Of the total variance, direct effects for BW accounted for $47 \%$ and maternal effects for $40 \%$. For CI, the effects of sire of dam, parity of dam and year of birth were significant, and the regression coefficient of CI on direct inbreeding was 1.4. For BW, the effects of year of birth within period, sex, age of dam and linear and quadratic inbreeding of calf were significant. The effect of year of birth was significant for WW. Regression coefficient of WW on maternal inbreeding was $-0.51 \pm 0,14 \mathrm{~kg}$.
\end{abstract}

Key Words: breeding value, Brown Swiss, calving interval, inbreeding, weights

\section{Introdução}

A endogamia e a seleção foram combinadas de forma eficaz nos primeiros criatórios de animais domésticos com o propósito de estabelecer as populações que serviriam de base para o melhoramento de seus animais. O estudo do fenômeno da endogamia nas populações de bovinos é de vital importância, principalmente onde as técnicas de inseminação arti- ficial têm sido largamente utilizadas. Segundo YOUNG (1984), o ganho genético por intermédio da seleção tem ocorrido rapidamente, especialmente nos rebanhos leiteiros, como resultado de touros geneticamente superiores deixarem milhares de filhas e seus filhos serem selecionados para as centrais de inseminação artificial. Apesar deste ganho, é preocupante o uso extensivo de poucos touros de grande valor genético, pois isto pode levar à redução

\footnotetext{
1 Parte da dissertação de mestrado apresentada pelo primeiro autor ao Depto. de Zootecnia da UFC

2 Doutorando, MSc, Universidade Estadual de Maringá. Av. Colombo, 5790, Maringá-PR - CEP: 87028-900. E.mail: alencariano@hotmail.com

3 Professor, PhD., Depto de Zootecnia da Universidade Federal do Ceará, Caixa Postal 12167. CEP: 60021-970, Fortaleza-CE.

4 Pesquisador da EMBRAPA Cerrados - Arroz e Feijão, Planaltina - DF. Bolsista do CNPq. E.mail: mclaudio@cnpaf.embrapa.br

5 Professor, PhD, UNIFI, Dipartimento di Scienze Zootecniche - Universitá degli Studi di Firenze, Italia. E.mail: riccardo.bozzi@unifi.it
} 
da variabilidade genética e a efeitos deletérios decorrentes da endogamia.

A endogamia ocorre quando os acasalamentos são efetuados entre parentes mais próximos do que seriam se os indivíduos tivessem sido escolhidos ao acaso de uma população. Os indivíduos aparentados têm um ou mais ancestrais em comum e, portanto, a extensão da endogamia está relacionada à quantidade de ancestrais que é compartilhada pelos pais dos indivíduos endogâmicos. Oefeito primário daendogamia é provocar o surgimento de mais pares de genes em homozigose, diminuindo concomitantemente a porcentagem de heterozigotos, acarretando, dessa forma, manifestações de muitos genes recessivos, os quais, geralmente, provocam alguma degeneração na média do mérito individual. Existem duas causas possíveis do declínio da média do valor fenotípico, de características quantitativas, provocado pela endogamia. A primeira é que os genes favoráveis tendem a ser dominantes ou parcialmente dominantes, e a segunda é o fato do heterozigoto ter um valor fenotípico maior que o homozigoto (LUSH, 1945; CROW e KIMURA, 1970).

Os efeitos adversos da endogamia na habilidade reprodutiva de vacas e novilhas têm sido observados tanto em trabalhos experimentais como em estudos realizados a partir de dados de campo, principalmente nas regiões temperadas, evidenciando, assim, que as características associadas ao valor adaptativo são as mais afetadas (YOUNG et al., 1969; GUARAGNA, 1986; HERMAS et al., 1987; e MACNEIL et al., 1989). Na Índia, as investigações de REDDY e NAGARCENKAR (1990) mostraram evidências de efeitos depressivos devidos à endogamia sobre os intervalos de partos de bovinos da raça Sahiwal. Em dois rebanhos, as estimativas dos intervalos de partos e os coeficientes de endogamia $(F)$ foram 503,4 dias $(11,80 \%)$ e 445,5 dias $(8,88 \%)$, respectivamente. DIAS e OLIVEIRA (1994a) encontraram aumento de 1,36 dias nos intervalos de partos para cada $1 \%$ de aumento na endogamia, em oito rebanhos analisados. Os valores dos intervalos de partos e da endogamia foram 459,63 dias e 6,49\%, respectivamente.

Com respeito às características de crescimento, resultados de diversos trabalhos com diferentes raças (NELSON e LUSH, 1950; SWIGER et al., 1961; PARIACOTE et al., 1998; e QUEIROZ et al., 1998) apontam que a endogamia geralmente tende a reduzir a taxa de crescimento, afetando o desempenho dos animais. No entanto, TYLER et al. (1949) já ressalta- vam que a taxa de endogamia, praticada sem o risco de deteriorar o mérito genético do animal, depende do grau de dominância (incluindo a sobredominância), do verdadeiro mérito do estoque fundador, da herdabilidade e da intensidade de seleção para as características desejadas. No Brasil, praticamente não existem estudos sobre a extensão e a magnitude da endogamia e suas relações com características de crescimento em bovinos leiteiros de origem européia. Os estudos existentes são escassos e, geralmente, voltados para animais de corte (ALENCAR et al., 1981; AMARAL, 1986; e QUEIROZ et al., 1998).

THOMSON e FREEMAN (1967) conduziram um experimento, em um rebanho fechado de bovinos da raça Holandesa, para investigar os efeitos da endogamia, acompanhado de seleção, sobre a produção e o crescimento. A endogamia média e o coeficiente de regressão do peso aos 6 meses sobre a endogamia, foram $10,2 \%$ e $-0,29 \mathrm{~kg}$, respectivamente. $\mathrm{O}$ efeito detrimental da endogamia sobre o crescimento foi pronunciado até os 4 anos de idade das vacas. HILLERS e FREEMAN (1964), também em um rebanho experimental com bovinos da raça Guernsey, encontraram efeitos depressivos em virtude da endogamia sobre os pesos das vacas em todas as idades estudadas, ou seja, do nascimento aos 5 anos. A endogamia média do rebanho foi $6,4 \%$ e os coeficientes de regressão dos pesos ao nascer e aos 6 meses, $-0,33$ e - $0,68 \mathrm{lb}$, respectivamente. Com respeito a bovinos de corte, MACNEIL et al. (1989) observaram redução no peso ao nascer $(\mathrm{P}<0,05)$ atribuída à endogamia materna, comparando quatro linhagens endogâmicas $(\mathrm{F}=26,5 \%)$ e uma controle $(\mathrm{F}=6,9 \%)$ de bovinos Hereford. Dentro e entre as linhagens, verificou-se redução do peso à desmama, com aumento nos níveis de endogamia $(\mathrm{P}<0,05)$, no entanto, os bezerros das vacas endogâmicas desmamaram mais leves que os bezerros controle $(\mathrm{P}<0,05)$.

De acordo com FALCONER (1989), sob o efeito dispersivo da endogamia, ou da deriva genética, a freqüência gênica, em pequenas populações, tende em direção a valores extremos. Uma vez que os componentes de variância diminuem, à medida que as frequiências gênicas tendem àqueles valores, a variância genética aditiva nessas populações também tendem a decrescer.

Os objetivos deste trabalho foram estudar os efeitos da endogamia sobre o peso ao nascer, peso à desmama e intervalo de partos e avaliar seus efeitos sobre o valor genético do peso ao nascer de bovinos da raça Pardo-Suíça. 


\section{Material e Métodos}

O conjunto de dados e os registros genealógicos para determinação do parentesco e da endogamia, analisados neste estudo, foram coletados dos livros de registro genealógico do rebanho Pardo Suíço "puro de origem", pertencente à Universidade Federal do Ceará (UFC). A exploração do rebanho visava, basicamente, a difusão da raça entre os criadores, além de servir de suporte às aulas de zootecnia da UFC; era feita no campus da Escola de Agronomia, na cidade de Fortaleza, de 1945 até 1982, quando foi transferida para Fazenda Experimental Vale do Curu, no município de Pentecoste, a $100 \mathrm{~km}$ de Fortaleza.

As vacas foram ordenhadas manualmente pela manhã, sendo reservado o leite de duas tetas para o aleitamento dos bezerros, que a partir de um mês de idade eram aleitados artificialmente até os seis meses de idade, quando ocorria a desmama definitiva. Machos e fêmeas, submetidos ao manejo geral do rebanho, foram avaliados em termos de desenvolvimento ponderal e mensurações corporais, sendo as novilhas usadas para a reposição do rebanho; a maioria de machos e fêmeas descartados foi leiloada para criadores da região. Deve ser salientado que, em épocas não específicas e por períodos indeterminados, faltaram recursos financeiros para o programa, com conseqüências diretas sobre a qualidade da alimentação do rebanho.

O sistema de criação adotado foi o semi-extensivo na época das chuvas, ou seja, os animais foram levados a campos de pastagem nativa, onde permaneceram até as 11 horas, sendo então estabulados, tendo um manejo alimentar diferenciado para cada categoria animal. Basicamente, a alimentação fornecida foi constituída de a) forragens picadas de capim elefante (Pennisetum purpureum, Schum), canarana (Echinochloa polystachya (H.B.K., Hitch.), capim sempre verde (Panicum maximum, var. gongyloides Doell) e colonião (Panicum maximum, Jacq); b) silagem de milho (Zea mays, L), sorgo (Sorghum vulgare, L. Pers) e capim-elefante (Pennisetum purpureum, Schum); c) ração concentrada à base de farelo de trigo e farelo de algodão; d) mandioca (Manihot esculentas, Crantz) triturada e e) sal mineral à vontade. A partir de 1982, o rebanho foi transferido para a Fazenda Experimental e passou a ter o mesmo sistema semi-extensivo, no qual os animais permaneceram no pasto nativo da região durante o período chuvoso, sendo estabulados no período seco. A suplementação alimentar foi constituída de capim-elefante e sorgo (verde ou ensilado), e leucena (Leucaena leucocephala (Lam) de Wit) picada ou como feno e ração concentrada com nível de $22 \%$ de proteína e $78 \%$ de NDT. O manejo sanitário sempre incluiu vacinações contra febre aftosa, teste de brucelose anual e vermifugação. A monta natural foi o sistema de acasalamento predominante, exceto nos anos de 1968, 1969, 1980, durante o período de 1972 a 1978, quando foi usada também a inseminação artificial, não havendo estação de monta definida. Apresenta-se na Tabela 1 a distribuição dos bezerros por mês de nascimento.

A edição e criação de vários conjuntos de dados, as restrições pertinentes e as estatísticas elementares foram realizadas no SAS (1996) versão 6.12. Foram analisados 996 dados de peso ao nascer (PN) de 1048 animais, filhos de 28 touros e 334 vacas, nascidos durante o período de 1946 a 1988; 395 dados de peso à desmama (PD) de 612 animais, filhos de 16 touros e 205 vacas, nascidos no período de 1952 a 1973 e 705 obser-

Tabela 1 - Distribuição dos bezerros de acordo com o mês de nascimento

Table 1 - Distribution of the calves by birth month

\begin{tabular}{|c|c|}
\hline $\begin{array}{l}\text { Mês de nascimento } \\
\text { Month of birth }\end{array}$ & $\begin{array}{l}\text { Número de bezerros } \\
\text { Number of calves }\end{array}$ \\
\hline Janeiro & 75 \\
\hline January & \\
\hline Fevereiro & 52 \\
\hline February & \\
\hline Março & 85 \\
\hline March & \\
\hline Abril & 99 \\
\hline April & \\
\hline Maio & 89 \\
\hline May & \\
\hline Junho & 135 \\
\hline June & \\
\hline Julho & 122 \\
\hline July & \\
\hline Agosto & 104 \\
\hline August & \\
\hline Setembro & 97 \\
\hline September & \\
\hline Outubro & 92 \\
\hline October & \\
\hline Novembro & 96 \\
\hline November & \\
\hline Dezembro & 85 \\
\hline December & \\
\hline Total & 1131 \\
\hline
\end{tabular}


vações de intervalos de partos (IDP) de 320 vacas, filhas de 25 touros e 163 vacas, durante os anos de 1948 a 1993.

O coeficiente de endogamia foi calculado para cada animal e para o rebanho, de acordo com o método proposto por WRIGHT (1923), utilizandose o programa computacional MTDFNRM ("Multiple Trait Derivative Free Numerator Relationship Matrix"), que compõe o software MTDFREML, descrito por BOLDMAN et al. (1995). As análises estatísticas das características foram realizadas por intermédio do Método dos Quadrados Mínimos, utilizando-se o procedimento "General Linear Models" do SAS (1996).

Para a análise de PN foram considerados os efeitos fixos do mês, período (1946 a 1982 e 1983 a 1988), ano de nascimento dentro de período, sexo, categoria de idade da vaca ao parto, os efeitos lineares e quadráticos da endogamia direta $(\mathrm{Fd})$ e materna $(\mathrm{Fm})$ como covariáveis e os efeitos aleatórios de touro. Para o PD foram considerados os efeitos de ano, mês, sexo, categoria da vaca (fixos), Fd e Fm linear e quadrático e touro (aleatório). A análise do IEP incluiu os efeitos fixos do sexo da cria atual, mês e ano de parição, ordem de parto e os efeitos aleatório do pai da vaca. Os efeitos lineares e quadráticos da endogamia da vaca que gerou o IDP foram estudados como covariável. O modelo I, em notação matricial, foi aplicado nas análises das três características:

$$
\mathrm{Y}=\mathrm{X} \beta+\mathrm{Za}+\mathrm{e}
$$

em que $Y$ é o vetor das observações; $\beta$, o vetor dos efeitos fixos; a, o vetor das variáveis aleatórias, e o vetor dos resíduos e $\mathrm{X}$ e $\mathrm{Z}$, as matrizes de incidência.

Os valores genéticos direto $\left(\mathrm{VG}_{\mathrm{d}}\right)$ e materno $\left(\mathrm{VG}_{\mathrm{m}}\right)$ para o $\mathrm{PN}$ foram preditos a partir da solução das equações dos modelos mistos. Os componentes de variâncias e covariâncias necessários à obtenção dos BLUP (Melhor Preditor Linear não-Viesado) do mérito genético dos animais foram estimados pelo Método da Máxima Verossimilhança Restrita Livre de Derivadas (SMITH e GRASER, 1986), utilizando o aplicativo MTDFREML (BOLDMAN et al., 1995).

O modelo matemático incluiu como fixo os efeitos da subclasse ano-mês de nascimento e sexo do animal (grupo contemporâneo) e classe de idade da vaca ao parto, tendo a parte aleatória as contribuições dos efeitos genético direto, materno e de ambiente permanente. A equação III, em notação matricial, descreve o modelo adotado para a análise do PN, assumindo um modelo animal:

$$
Y=X \beta+Z_{1} a+Z_{2} m+Z_{3} p+e
$$

em que $Y$ é o vetor das observações, $\beta$, vetor dos efeitos fixos; $a$, o vetor dos efeitos genéticos aditivos diretos, $\mathrm{m}$ o vetor das contribuições maternas (efeito genético aditivo materno); $p$, o vetor das contribuições de ambiente permanente; $e$, o vetor de resíduos; e $X$ $Z_{1}, Z_{2}$ e $Z_{3}$, matrizes de incidência. A seguinte distribuição conjunta para os efeitos aleatórios foi assumida,

$$
\left[\begin{array}{c}
\mathrm{y} \\
\tilde{\mathrm{a}} \\
\tilde{\mathrm{m}} \\
\tilde{\mathrm{p}} \\
\tilde{\mathrm{e}} \\
\sim
\end{array}\right] \sim \mathrm{NMV}\left\{\left[\begin{array}{c}
\mathrm{X} \beta \\
\tilde{0} \\
\tilde{0} \\
\tilde{0} \\
\tilde{0} \\
\tilde{\sim}
\end{array}\right],\left[\begin{array}{ccccc}
\mathrm{V} & \mathrm{Z}_{1} \mathrm{G} & \mathrm{Z}_{2} \mathrm{M} & \mathrm{Z}_{3} \mathrm{P} & \mathrm{R} \\
\mathrm{GZ} & \mathrm{G} & \mathrm{C} & \phi & \phi \\
\mathrm{MZ}_{2}^{\prime} & \mathrm{C} & \mathrm{M} & \phi & \phi \\
\mathrm{PZ}_{3}^{\prime} & \phi & \phi & \mathrm{P} & \phi \\
\mathrm{R} & \phi & \phi & \phi & \mathrm{R}
\end{array}\right]\right\}
$$

em que

$\mathrm{V}=\mathrm{Vaf}(\mathrm{y}), \mathrm{G}=\mathrm{A} \sigma_{\mathrm{a}}^{2}, \mathrm{M}=\mathrm{A} \sigma_{\mathrm{m}}^{2}, \mathrm{C}=\mathrm{A} \sigma_{\mathrm{am}}, \mathrm{P}=\mathrm{I}_{\mathrm{m}} \sigma_{\mathrm{p}}^{2} \mathrm{e} \mathrm{R}=\mathrm{I}_{\mathrm{n}} \sigma_{\mathrm{e}}^{2}$ $m$ é número total de vacas; $n$, número de observações; $G, M, P$ e $R$, as matrizes de (co)variâncias genética direta, materna, de ambiente permanente e residual, respectivamente; $A$, a matriz dos coeficientes de parentesco entre os animais; $C$, a matriz de covariância genética entre os efeitos direto e materno; $I$, uma matriz identidade; $\phi$, um vetor nulo; $\sigma_{a}^{2}$, a variância genética aditiva direta, $\sigma_{\mathrm{m}}^{2}$, a variância genética aditiva materna, $\sigma_{\mathrm{p}}^{2}$, a variância de ambiente permanente materno, $\sigma_{\mathrm{am}}$, a covariância entre os efeitos genéticos direto e materno e $\sigma_{\mathrm{e}}^{2}$, a variância residual.

\section{Resultados e Discussão}

$\mathrm{Na}$ matriz de parentesco, foram usados 1209 animais para o cálculo dos coeficientes de endogamia dos indivíduos e do rebanho, cujos valores médio e máximo foram 12,50 e 38,3\%, respectivamente. Estes valores podem ser considerados moderados, quando comparados aos encontrados nos estudos de NELSON e LUSH (1950) e MACNEIL et al. (1989), porém estão acima dos valores estimados por THOMSON e FREEMAN (1967) e DIAS e OLIVEIRA (1994a).

Na Tabela 2 é apresentada a distribuição dos animais por classe de endogamia. Os acasalamentos endogâmicos mais freqüentes ocorreram entre meioirmãos paternos e maternos, como sugerem as quatro 
últimas classes. As médias dos coeficientes de endogamia das progênies dos touros mais influentes no rebanho, exibidas na Tabela 3, mostram que os touros Marquês do Ceará-RGD 5145 e Javali-RGN 299, ambos originários do rebanho, foram os que apresentaram maior grau de parentesco com as vacas por eles cobertas, predominando o acasalamento entre meio-irmãos paternos e maternos e entre meioprimos, enquanto entre os touros importados predominou o acasalamento com as filhas e netas. É interessante notar que, apesar de ter deixado maior número de progênie que os demais touros, o parentesco de Moreno-RGD 104 com as vacas foi baixo.

Apesar de a endogamia ter alcançado valores

Tabela 2 - Distribuição dos animais por classes de endogamia

Table 2 - Distribution of animals by classes of inbreeding

\begin{tabular}{lc}
\hline $\begin{array}{l}\text { Classe de endogamia } \\
\text { Class of inbreeding }\end{array}$ & $\begin{array}{c}\text { Número de animais } \\
\text { Number of animals }\end{array}$ \\
\hline $1-0,00$ & 525 \\
$2-0,00-\mid 0,05$ & 184 \\
$3-0,05-0,10$ & 194 \\
$4-0,10-0,15$ & 107 \\
$5-0,15-0,20$ & 35 \\
$6-0,20-\mid 0,25$ & 48 \\
$7->0,25$ & 38 \\
Total & 1131 \\
\hline
\end{tabular}

Tabela 3 - Média dos coeficientes de endogamia da progênie $\left(F_{P}\right)$ dos touros mais importantes, o número de progênie $\left(\mathrm{N}_{\mathrm{P}}\right)$ e o parentesco aditivo entre o touro e a vaca $\left(\mathrm{R}_{\mathrm{TV}}\right)$

Table 3 - Average inbreeding coefficient of the outstanding sires progeny $\left(F_{P}\right)$, number of progeny $\left(N_{P}\right)$ and the relationship of sire to dam $\left(R_{S D}\right)$

\begin{tabular}{lrrr}
\multicolumn{4}{c}{ relationship of sire to dam $\left(R_{S D}\right.$} \\
\hline Touro & $\mathrm{N}_{\mathrm{P}}$ & $\mathrm{F}_{\mathrm{P}}(\%)$ & $\mathrm{R}_{\mathrm{TV}}(\%)$ \\
Sire & $N_{P}$ & \multicolumn{1}{c}{$F_{P}$} & $R_{S D}$ \\
\hline Marquês do Ceará-RGD 5145 $^{1}$ & 56 & 14,00 & 27,90 \\
Javali-RGN 299 $^{1}$ & 56 & 11,90 & 23,80 \\
Dote de Pinheiro-RGD 1635 $^{2}$ & 150 & 9,40 & 18,80 \\
Heleno de Tijipió-RGD 2285 $^{2}$ & 56 & 8,10 & 16,30 \\
Reno do Ceará-RGD 4151 $^{1}$ & 85 & 7,76 & 15,50 \\
Cel. Marcel-RGD 2215 $^{2}$ & 50 & 7,60 & 15,10 \\
Daniel Paul-RGD 4625 $^{2}$ & 75 & 3,30 & 6,70 \\
Moreno-RGN 104 $^{2}$ & 138 & 2,90 & 5,80
\end{tabular}

\footnotetext{
1 nascido no rebanho, ${ }^{2}$ importado.
}

1 born in the herd, ${ }^{2}$ imported. altos, não foi encontrado, nas fichas zootécnicas dos animais, registro de doenças cuja etiologia possa ser atribuída às manifestações de genes recessivos letais ou semi-letais. As possíveis causas da ausência de anomalias foram a descontinuidade dos acasalamentos endogâmicos, principalmente em linha, o estoque fundador e os demais reprodutores não terem sido portadores, ou simplesmente a perda de registro, devido à dificuldade de se observar este fenômeno.

As tendências da média anual da endogamia das vacas e dos produtos endogâmicos são mostradas na Figura 1. Durante os seis primeiros anos, a endogamia foi praticamente zero, período que correspondeu à formação do rebanho onde os animais fundadores eram pouco aparentados, ou de genealogia desconhecida. Também pode-se constatar que neste período foram perdidas muitas informações de pedigree, impossibilitando, dessa forma, o estabelecimento dos laços de parentesco. Os períodos em que ocorreram comportamento crescente e esperado da endogamia devem-se principalmente ao uso intensivo de poucos touros, geralmente importados, ou da inseminação artificial. As quedas abruptas da endogamia coincidem com a substituição ou introdução de novo reprodutor, sem nenhum laço de parentesco com os animais do rebanho.

Na Figura 2 é mostrado o comportamento da curva dos valores genéticos direto (VGD) e materno (VGM) para o PN, em função do ano de nascimento dos animais. Pode-se observar grande flutuação dos VGD ao longo dos anos, oscilando entre valores

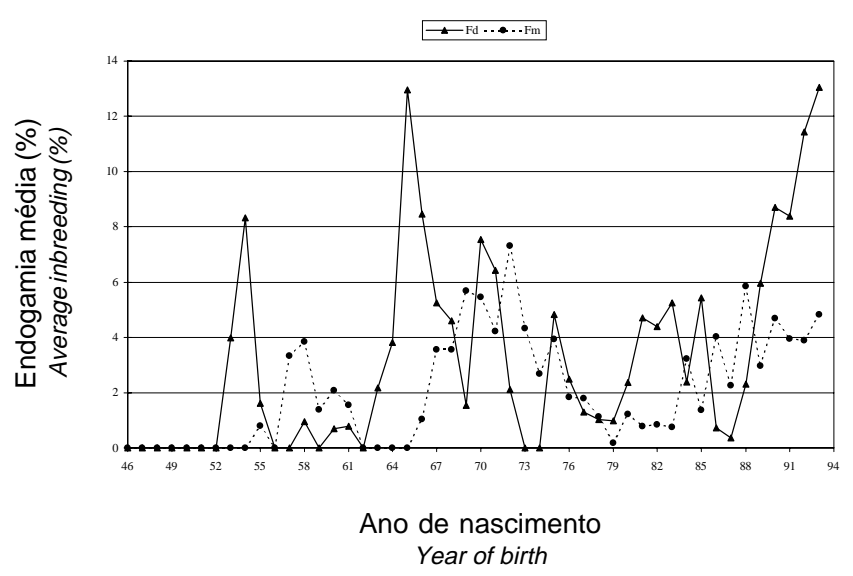

Figura 1 - Tendência da média anual da endogamia das vacas $\left(F_{m}\right)$ e de suas crias $\left(F_{d}\right)$, de acordo com o ano de nascimento.

Figure 1 - Trends for annual average inbreeding of calves $\left(F_{d}\right)$ and of dams $\left(F_{m}\right)$ by year of birth. 
positivos e negativos. Comparando-se as Figuras 1 e 2, pode-se observar que, nos períodos de 1962 a 1970 e de 1975 a 1980, a endogamia direta e o VGD tiveram tendências similares, istoé, ao aumento de um seguiu-se um acréscimo no outro, do mesmo modo que a diminuição em um causou redução no outro. Entretanto, nos períodos de 1952 a 1958 e de 1984 a 1993, os aumentos nos níveis de endogamia foram acompanhados de redução no mérito genético individual, possivelmente, devido à diminuição na variância genética aditiva, fenômeno teoricamente esperado em populações endogâmicas (ROBERTSON, 1961), visto que, a depressão devida a endogamia reduz o desempenho dos animais. Para o período estudado, VGM para o peso ao nascer teve maior incremento que o VGD, assumindo quase sempre valores positivos (Figura 2). Possivelmente a endogamia não afetou o mérito genético das vacas. Os efeitos genéticos aditivos direto foram responsáveis por aproximadamente $47 \%$ da variação do PN, enquanto os efeitos aditivos maternos responderam por $40 \%$ da variação total.

Estes resultados diferiram daqueles estimados por PARIACOTE et al. (1998), em que os valores para os efeitos genéticos diretos foram maiores que os valores para o efeito materno, ao longo dos anos. MACNEIL et al. (1992) encontraram tendências positivas dos valores genéticos direto e materno para o peso ao nascer; os primeiros foram responsáveis por $73 \%$ no aumento desta característica, enquanto os últimos explicaram $27 \%$ do aumento genético.

A média observada, o desvio-padrão, os valores de mínimo e máximo e o coeficiente de variação do IDP foram 473,50 dias, 111,67 dias, 330,90 a 798,40 dias e $21,81 \%$, respectivamente. A média encontrada neste trabalho está acima do preconizado como ideal, que é um intervalo de 365 dias. O resumo da análise de variância para o IDP encontra-se na Tabela 4 e mostra que a ordem de parição foi a mais importante fonte de variação para esta característica $(\mathrm{P}<0,01)$.

Também foram significativas fontes de variação o pai da vaca $(\mathrm{P}<0,01)$, refletindo diferenças genéticas entre os touros e o ano de nascimento $(\mathrm{P}<0,01)$. Apesar de não ter havido significância estatística da endogamia direta sobre o IDP, foi estimado acréscimo de 1,4 dias no IDP para cada $1 \%$ de aumento na endogamia direta, conforme mostrado na Tabela 5 .

Nos trabalhos de HUDSON e VAN VLECK (1984), QUEIROZ (1992) e DIAS et al. (1994), também não foram encontrados resultados significativos da endogamia sobre o intervalo de partos. No entanto, REDDY e NAGARCENKAR (1990) e DIAS e OLIVEIRA (1994a) relataram efeito depressivo da endogamia sobre o IDP. No conjunto de dados utilizados para estudar o IDP, a média do coeficiente de endogamia direta foi 0,041 e $62 \%$ das

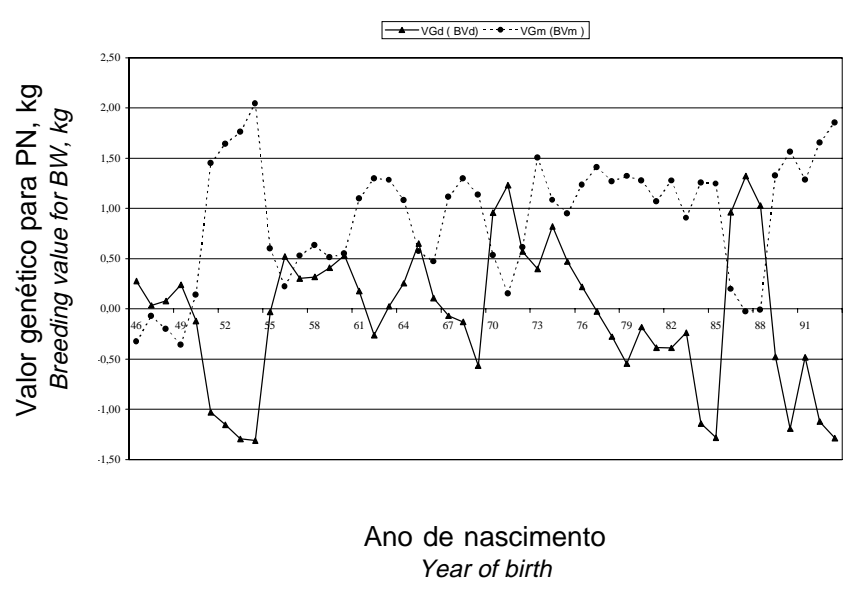

Figura 2 - Comportamento dos valores genéticos direto $\left(V G_{d}\right)$ e materno $\left(V G_{m}\right)$ para o peso ao nascer.

Figure 2 - Average direct $\left(B V_{d}\right)$ and maternal $\left(B V_{m}\right)$ breeding values for birth weight.

Tabela 4 - Resumo da análise de variância por quadrados mínimos dos intervalos de parto

Table 4 - Means squares from least squares analysis for calving interval

Fontes de variação Grau de liberdade Quadrado médio Source of variation Degree offreedom Mean square

\begin{tabular}{lcc}
\hline Pai da vaca & 21 & $27.875^{* *}$ \\
$\begin{array}{l}\text { Sire of dam } \\
\text { Sexo da cria }\end{array}$ & 1 & 22.666 \\
$\begin{array}{l}\text { Sex } \\
\text { Mês de nascimento }\end{array}$ & 11 & 13.141 \\
$\begin{array}{l}\text { Month of birth } \\
\text { Ano de nascimento }\end{array}$ & 45 & $23.160^{* *}$ \\
$\begin{array}{l}\text { Year of birth } \\
\text { Ordem de parição }\end{array}$ & 9 & $60.865^{* *}$ \\
$\begin{array}{l}\text { Parity } \\
\text { Endogamia direta }\end{array}$ & & \\
$\begin{array}{l}\text { Directinbreeding } \\
\text { Linear }\end{array}$ & & \\
$\begin{array}{l}\text { Linear } \\
\text { Quadrática }\end{array}$ & 1 & 08.420 \\
Quadratic & & \\
Resíduo & 1 & 06.674 \\
Error & & \\
$\mathrm{R}^{2}(\%)$ & 488 & \\
** (P<0,01) & 28 &
\end{tabular}

${ }_{\star \star *}(\mathrm{P}<0,01)$. 
Tabela 5 - Coeficiente de regressão do peso ao nascer (bPN), peso à desmama (bPD) e intervalo de partos (bIDP), com respectivos erros-padrão (EP), sobre a porcentagem da endogamia direta ( $\mathrm{Fd}, \%)$ e materna ( $\mathrm{Fm}, \%)$

Table 5 - Regression coefficients with standard errors (SE) of birth weight (bBW), weaning weight $(b W W)$ and calving interval $(\mathrm{bCl})$ on direct and maternal inbreeding percentage

\begin{tabular}{lccc}
\hline & $\mathrm{b}_{\mathrm{PN}} \pm \mathrm{EP}(\mathrm{kg})$ & $\mathrm{b}_{\mathrm{PD}} \pm \mathrm{EP}(\mathrm{kg})$ & $\mathrm{b}_{\mathrm{IDP}} \pm \mathrm{EP}($ dias $)$ \\
& $b_{B W} \pm S E(\mathrm{~kg})$ & $b_{W W} \pm S E(\mathrm{~kg})$ & $b_{C I} \pm S E$ (days) \\
\hline $\mathrm{Fd}$ & $-0,02 \pm 0,02$ & $-0,51 \pm 0,14^{* *}$ & $1,35 \pm 0,53^{*}$ \\
$\mathrm{Fm}$ & $0,05 \pm 0,02$ & $-0,16 \pm 0,15$ & - \\
& $-1,68 \pm 0,28^{* *}$ & $0,42 \pm 1,54$ & $0,18 \pm 5,80$ \\
& $-0,43 \pm 0,25$ & $0,60 \pm 1,76$ & - \\
\hline
\end{tabular}

${ }^{* *} \mathrm{P}<0,01 ;{ }^{*} \mathrm{P}<0,05$

vacas possuíam endogamia igual a zero, de forma que é provável que valores de pequena magnitude não tenham provocado variação nesta característica, sensível ao teste estatístico. As vacas, objeto deste estudo, que constam no arquivo de dados são aquelas que tiveram pelo menos dois partos (condição para que haja um intervalo de partos), portanto, não foram consideradas as novilhas que morreram antes do segundo parto, bem como as descartadas por problemas reprodutivos, o que implica em um processo seletivo, mantendo no rebanho somente os animais que apresentaram melhor desempenho reprodutivo. Dessa forma, é possível que animais com reduzida taxa de concepção, puberdade tardia, elevado número de serviços por concepção e com histórico de aborto, devido à elevada endogamia, não tenham sido considerados no arquivo de dados e, portanto, não foi possível a sua avaliação neste estudo. Esta hipótese é reforçada pela ficha zootécnica dos animais, na qual se podem constatar ocorrências de natimortos, abortos, distocia, ou seja, vários problemas de natureza reprodutiva. Tendo em vista tratar-se de um rebanho experimental, com um número relativamente pequeno de fêmeas, poder-se-ia esperar que os valores do IDP fossem mais próximos do que é considerado ideal, por ser uma das características de maior importância econômica. Os resultados pouco satisfatórios do IDP, obtidos neste estudo, mostram que, provavelmente, o descarte de vacas velhas e vacas com problemas reprodutivos não foram promovidos adequadamente (pode ser atribuído também a entraves administrativos) e, por conseguinte, inadequado manejo reprodutivo elevou os valores do IDP.

As médias ajustadas do PN para machos e fêmeas, com respectivos erros-padrão, o coeficiente de variação e os valores de mínimo e máximo foram $36,29 \pm 0,55 \mathrm{~kg}, 34,39 \pm 0,54 \mathrm{~kg}, 13,55 \%, 21$ e $50 \mathrm{~kg}$, respectivamente. Os resultados da análise de variância para PN (Tabela 6) mostram que todos os efeitos foram significativos $(\mathrm{P}<0,05)$, exceto os efeitos de touro, mês e período de nascimento e a endogamia materna. A depressão devida aos efeitos da endogamia direta sobre o PN $(\mathrm{P}<0,05)$, observada neste estudo, também já fora relatada em diversos trabalhos (HILLERS e FREEMAN, 1964; MACNEIL et al., 1989; PARIACOTE et al., 1998). Resultados não-significativos da endogamia materna sobre o PN também foram encontrados por NELSON e LUSH (1950) e MACNEIL et al. (1992). O efeito da endogamia direta $(\mathrm{P}<0,01)$ sobre o PN teve um comportamento quadrático (Tabela 5), como pode ser observado na Figura 3, cuja curva ajustada pela equação $\hat{\mathrm{Y}}_{\mathrm{PN}}=36+0,37 \mathrm{~F}-1,68 \mathrm{~F}^{2}$, mostra que o valor do PN será máximo, quando $\mathrm{F}$ se aproximar de $11 \%$. Portanto, é possível que a endogamia se manifeste adversamente a partir de níveis superiores a $11 \%$.

Observa-se, na Tabela 7, que houve aumento nas médias ajustadas do PN até a classe de $10 \%$ de endogamia. No entanto, a partir do nível de $10 \%$ de endogamia, pode-se constatar diminuição na média do $\mathrm{PN}$. A média da classe $\mathrm{F}=0$ ficou muito próxima à dos animais incluídos na classe que compreende endogamia entre 15 e $20 \%$. Estes resultados sugerem que, a partir de certo nível de F, provavelmente a média do PN tenderá a se reduzir, devido aos efeitos depressivos causados pela endogamia.

$\mathrm{O}$ efeito quadrático da endogamia sobre o PN concorda com a afirmação de CROW e KIMURA (1970) de que este comportamento é observado quando há existência da dominância e da ação gênica epistática do tipo dominante-dominante, na constituição genética dos indivíduos. Considerando que a endogamia aumenta o número de pares de genes em homozigose e a freqüência de recessivos, diminuindo 
FALCÃO et al.

concomitantemente a porcentagem de heterozigotos, é esperado que o declínio observado na média do peso ao nascer tenha sido devido à endogamia.

As médias ajustadas do PD para machos e fêmeas com seus respectivos erros-padrão, o coeficiente de variação e os valores de mínimo e máximo foram $122,07 \pm 3,33 \mathrm{~kg}, 117,32 \pm 3,19 \mathrm{~kg}, 17,37 \%, 80$ e $180 \mathrm{~kg}$, respectivamente. $\mathrm{O}$ resumo da análise de variância apresentado na Tabela 6 mostra que a endogamia direta e materna não afetaram significativamente $o$ $\mathrm{PD}$ e apenas os efeitos de ano de nascimento $(\mathrm{P}<0,01)$ foi significativo. DINKEL et al. (1968) e MANGUS e BRINKS (1971) também não verificaram efeito depressivo sobre o peso à desmama, devido à endogamia materna. Entretanto, a maioria dos estudos mostra que tanto a endogamia direta como a materna afetam negativamente esta característica (HILLERS e FREEMAN, 1964; THOMSON e FREEMAN,
1967; MACNEIL et al., 1989). O coeficiente de regressão do PD sobre a endogamia direta foi significativamente diferente de zero $(\mathrm{P}<0,01)$, conforme mostrado na Tabela 5 , de forma que cada $1 \%$ de aumento no valor de $\mathrm{F}$ acarretou redução de $-0,51 \mathrm{~kg}$ no PD. Este valor ficou compreendido entre as estimativas encontradas por NELSON e LUSH (1950) e MACNEIL et al. (1989). As médias dos coeficientes de endogamia direta e materna no arquivo de dados do PD foram de baixa magnitude $(0,066$ e 0,043, respectivamente), valores que dificilmente provocariam redução significativa nesta característica. $\mathrm{Na}$ Tabela 8 encontram-se as médias ajustadas do peso à desmama de acordo com o nível de endogamia.

Pode-se observar que os valores do PD nas quatro primeiras classes de endogamia, que representam $88 \%$ dos animais no arquivo de dados desta característica, praticamente não diferiram entre si. A classe

Tabela 6 - Resumo das análises de variância dos pesos ao nascer (PN) e à desmama (PD) Table 6 - Analysis of variance for birth weight (BW) and weaning weight (WW)

\begin{tabular}{|c|c|c|c|c|}
\hline \multirow[t]{2}{*}{$\begin{array}{l}\text { Fontes de variação } \\
\text { Source of variation }\end{array}$} & \multicolumn{2}{|c|}{$\begin{array}{l}\text { Graus de liberdade } \\
\text { Degree offreedom }\end{array}$} & \multicolumn{2}{|c|}{$\begin{array}{l}\text { Quadrado médio } \\
\text { Mean square }\end{array}$} \\
\hline & $\begin{array}{l}\mathrm{PN} \\
B W\end{array}$ & $\begin{array}{l}\mathrm{PD} \\
W W\end{array}$ & $\begin{array}{l}\mathrm{PN} \\
B W\end{array}$ & $\begin{array}{l}\text { PD } \\
W W\end{array}$ \\
\hline $\begin{array}{l}\text { Touro } \\
\text { Sire }\end{array}$ & 26 & 14 & 22 & 255 \\
\hline $\begin{array}{l}\text { Ano de nascimento } \\
\text { Year of birth }\end{array}$ & - & 21 & - & $1912 * *$ \\
\hline $\begin{array}{l}\text { Ano de nascimento/período } \\
\text { Year of birth/period }\end{array}$ & 40 & - & $53 * *$ & - \\
\hline $\begin{array}{l}\text { Período } \\
\text { Period }\end{array}$ & 1 & - & 49 & - \\
\hline $\begin{array}{l}\text { Mês de nascimento } \\
\text { Month of birth }\end{array}$ & 11 & 11 & 35 & 433 \\
\hline $\begin{array}{l}\text { Sexo } \\
\text { Sex }\end{array}$ & 1 & 1 & $748 * *$ & 493 \\
\hline $\begin{array}{l}\text { Categoria de idade da vaca } \\
\text { Age of dam } \\
\text { Endogamia direta } \\
\text { Direct inbreeding }\end{array}$ & 4 & 4 & $464 * *$ & 183 \\
\hline $\begin{array}{l}\text { Linear } \\
\text { Linear }\end{array}$ & 1 & 1 & $107 *$ & 1 \\
\hline $\begin{array}{l}\text { Quadrática } \\
\text { Quadratic } \\
\text { Endogamia materna } \\
\text { Maternal inbreeding }\end{array}$ & 1 & 1 & $219 * *$ & 14 \\
\hline $\begin{array}{l}\text { Linear } \\
\text { Linear }\end{array}$ & 1 & 1 & 27 & 805 \\
\hline $\begin{array}{l}\text { Quadrática } \\
\text { Quadratic }\end{array}$ & 1 & 1 & 22 & 1117 \\
\hline Resíduo & 896 & 338 & 23 & 377 \\
\hline $\begin{array}{l}\text { Error } \\
\mathrm{R}^{2}(\%)\end{array}$ & & & 35 & 39 \\
\hline
\end{tabular}

** Significativo $(\mathrm{P}<0,01) ;{ }^{*}(\mathrm{P}<0,05)$ 
Rev. bras. zootec.

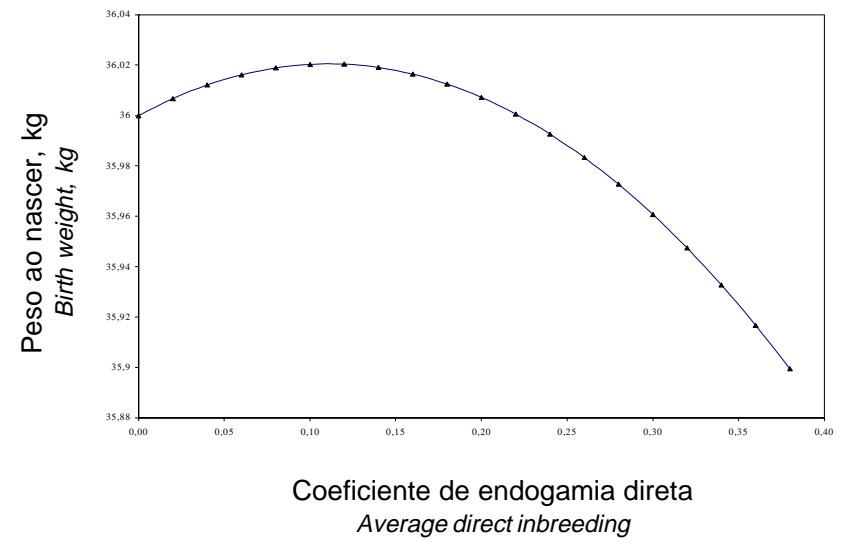

Figura 3 - Efeito da endogamia sobre o peso ao nascer. Figure 3 - The effect of direct inbreeding on birth weight.

Tabela 7 - Número de observações (N) e médias ajustadas $\left(\bar{X}_{\mathrm{PN}} \pm \mathrm{EP}\right)$ do peso ao nascer, segundo classe de endogamia

Table 7 - Least squares means $\left(\overline{\mathrm{X}}_{\mathrm{BW}}\right)$ and number of calf $(\mathrm{N})$ for birth weight by classes of inbreeding

\begin{tabular}{lrc}
\hline $\begin{array}{l}\text { Classes de endogamia } \\
\text { Classes of inbreeding }\end{array}$ & $\mathrm{N}$ & $\begin{array}{c}\overline{\mathrm{X}}_{\mathrm{PN}} \pm \mathrm{EP}(\mathrm{kg}) \\
\overline{\mathrm{X}}_{B W} \pm S E\end{array}$ \\
\hline $1-0,00$ & 485 & $36,00 \pm 0,58$ \\
$2-0,00-10,05$ & 161 & $36,62 \pm 0,67$ \\
$3-0,05-10,10$ & 173 & $37,44 \pm 0,71$ \\
$4-0,10-\mid 0,15$ & 80 & $35,86 \pm 0,80$ \\
$5-0,15-\mid 0,20$ & 18 & $36,29 \pm 1,37$ \\
$6-0,20-\mid 0,25$ & 44 & $35,95 \pm 0,94$ \\
$7->0,25$ & 34 & $33,86 \pm 1,09$ \\
Total & 995 & \\
\hline
\end{tabular}

Tabela 8 - Número de observações $(\mathrm{N})$ e médias ajustadas $\left(\overline{\mathrm{X}}_{\mathrm{PD}} \pm \mathrm{EP}\right)$ do peso à desmama, segundo a classe de endogamia

Table 8 - Least squares means $\left(\overline{\mathrm{X}}_{\mathrm{Ww}} \pm \mathrm{SE}\right)$ and number of calves $(N)$ for weaning weight by classes of inbreeding

\begin{tabular}{lcc}
\hline $\begin{array}{l}\text { Classes de endogamia } \\
\text { Classes of inbreeding }\end{array}$ & $\mathrm{N}$ & $\begin{array}{c}\overline{\mathrm{X}}_{\mathrm{PD}} \pm \mathrm{EP}(\mathrm{kg}) \\
\overline{\mathrm{X}}_{\mathrm{ww}} \pm \mathrm{SE}\end{array}$ \\
\hline $1-0,00$ & 193 & $122,44 \pm 3,76$ \\
$2-0,00-\mid 0,05$ & 123 & $122,52 \pm 4,01$ \\
$3-0,05-\mid 0,10$ & 159 & $119,06 \pm 3,94$ \\
$4-0,10-0,15$ & 65 & $122,59 \pm 4,81$ \\
$5-0,15-\mid 0,20$ & 14 & $126,51 \pm 7,56$ \\
$6-0,20-\mid 0,25$ & 29 & $120,36 \pm 6,07$ \\
$7->0,25$ & 29 & $108,26 \pm 6,00$ \\
Total & 612 & \\
\hline
\end{tabular}

seguinte contém os animais mais pesados na desmama. A partir da $5^{\mathrm{a}}$ classe de endogamia, a média do PD cai drasticamente, entretanto, devido ao reduzido número de observações, não é possível concluir se esta queda nos valores de PD é decorrente da endogamia, ou simplesmente ao acaso. Portanto, a falta de evidência de efeito detrimental da endogamia sobre o PD pode ser atribuída à baixa magnitude dos níveis de endogamia, decorrente da quantidade insuficiente de dados. Dessa forma, é necessária maior quantidade de dados para se obterem estimativas mais acuradas da magnitude da depressão devido à endogamia.

\section{Conclusões}

A média da endogamia do rebanho pode ser considerada moderada, quando comparada à de outros estudos.

Os resultados deste estudo indicaram que, de modo geral, a endogamia direta provocou redução no mérito genético individual para o peso ao nascer, possivelmente, devido à redução na variância genética aditiva. Entretanto, os níveis de endogamia não foram suficientes para afetar o mérito genético das vacas.

\section{Referências Bibliográficas}

ALENCAR, M.M., SILVA, A.H.G., BARBOSA, P.F. 1981. Efeitos da consangüinidade sobre os pesos ao nascimento e à desmama de bezerros da raça Canchim. R. Soc. Bras. Zootec., 10(1):156-172.

AMARAL, C.O. Efeito da endogamia sobre a reprodução e crescimento de bovinos da raça Nelore. Ribeirão Preto, SP: FMRP, 1989. 114p. Dissertação (Mestrado em Ciências) Faculdade de Medicina de Ribeirão Preto/Universidade de São Paulo, 1986.

BOLDMAN, K.G., KRIESE, L.A., VAN VLECK, L.D. et al. 1995. A manual for use of MTDFREML. A set of programs to obtain estimates of variance and covariances [DRAFT]. Lincoln: Department of Agriculture/Agricultural Research Service. $120 \mathrm{p}$.

CROW, J.F., KIMURA, M. 1970. An introduction to population genetics theory. Minneapolis: Alpha Editions. 591p.

DIAS, A.C., QUEIROZ, S.A., ALBUQUERQUE, L.G. 1994. Efeito da endogamia em características reprodutivas de bovinos da raça Caracu. R. Soc. Bras. Zootec., 23(2):157-164.

DIAS, F.M.G.N., OLIVEIRA, H.N. Efeito da consangüinidade sobre o intervalo entre partos (IEP) de fêmeas da raça Nelore. In: REUNIÃO ANUAL DA SOCIEDADE BRASILEIRA DE ZOOTECNIA, 31, 1994, Maringá. Anais... Maringá: SBZ, 1994a. p.173.

DIAS, F.M.G.N., OLIVEIRA, H.N. Efeito da consangüinidade sobre os pesos à desmama e a um ano de idade de bovinos da raça Nelore. In: REUNIÃO ANUAL DA SOCIEDADE BRASILEIRA DE ZOOTECNIA, 31, 1994, Maringá. Anais... Maringá: SBZ, 1994b. p.174. 
DINKEL, C.A., BUSCH, D.A., MINYARD, J.A. et al. 1968. Effects of inbreeding on growth and conformation of beef cattle. J. Anim. Sci., 27:313-322.

FALCONER, D.S. 1989. Introduction to quantitative genetics. 3.ed. New York: Logman Scientific \& Technical. 438p.

GUARAGNA, G.P. Reprodução e endogamia em bovinos Mantiqueira. Ribeirão Preto, SP: FMRP, 1986. 136p. Tese (Doutorado em Ciências) - Faculdade de Medicina de Ribeirão Preto/Universidade de São Paulo, 1986.

HERMAS, S.A., YOUNG, C.W., RUST, J.W. 1987. Effects of mild inbreeding on productive and reproductive performance of Guernsey cattle. J. Dairy Sci., 70(3):712-715.

HILLERS, J., FREEMAN, A.E. 1964. Effects of inbreeding and selection in a closed Guernsey herd. J. Dairy Sci., 47:894-897.

HUDSON, G.F.S., VAN VLECK, L.D. 1984. Inbreeding of artificially bred dairy cattle in the northeastern United States. J. Diary Sci., 67(1):161-170.

LUSH, J.L. 1945. Animal breeding plans. 3 ed. Ames: Iowa State College Press. 443p.

MACNEIL, M.D., DEARBORN, D.D., CUNDIFF, L.V. et al. 1989. Effects of inbreeding and heterosis in Hereford females on fertilility, calf survival and preweaning growth. J. Anim. Sci., 67:895-901.

MACNEIL, M.D., URICK, J.J., NEWMAN, S. et al. 1992. Selection for postweaning growth in inbred Hereford cattle: The Fort Keogh, Montana line I example. J. Anim. Sci., 70:723-733.

MANGUS, W.L., BKINKS, J.S. 1971. Relationships between direct and maternal effects on growth in Herefords: I. Environmental factors during preweaning growth. J. Anim. Sci., 32:17-25.

NELSON, R.H., LUSH, J.L. 1950. Effects of mild inbreeding on a herd of Holstein-Friesian cattle. J. Anim. Sci., 33:186-193.

PARIACOTE, F., VAN VLECK, L.D., MACNEIL, M.D. 1998. Effects of inbreeding and heterozygosity on preweaning traits in a closed population of Herefords under selection. J. Anim. Sci., 76:1303-1310.

QUEIROZ, S.A. Estudo da endogamia na raça Gir. Ribeirão Preto, SP: FMRP, 1992. 121p. Tese (Doutorado em Ciências) - Faculdade de Medicina de Ribeirão Preto/Universidade de São Paulo, 1992.
QUEIROZ, S.A., ALBUQUERQUE, L.G., LANZONI, N.A. Efeito da endogamia sobre o crescimento de bovinos da raça Gir no Brasil. In: REUNIÃO ANUAL DA SOCIEDADE BRASILEIRA DEZOOTECNIA, 35, 1998, Botucatu. Anais... Botucatu: SBZ, 1998. p.285-287.

REDDY, K.M., NAGARCENKAR, R. 1990. Effect of inbreeding on economic traits in Sahiwal cattle. Ind. J. Anim. Sci., 60(6):693-699.

ROBERTSON, A. 1961. Inbreeding in artificial selection programmes. Genet. Res., 2:189-194.

SAS Institute Inc. SAS user's guide for Windows Environment: 6.12. Cary, NC, SAS Institute: 1996. 79p.

SMITH, S.P., GRASER, H.U. 1986. Estimating variance components in a class of mixed models by restricted maximum likelihood. J. Dairy. Sci., 69:1156-1165.

SWIGER, L.A., GREGORY, K.E., KOCH, R.M. et al. 1961. Effect of inbreeding on performance traits of beef cattle. J. Anim. Sci., 20(3):626-630.

THOMSON, G.M., FREEMAN, A.E. 1967. Effects of inbreeding and selection in a closed Holstein-Friesian herd. J. Dairy Sci., 50(11):1824-1827.

TYLER, W.J., CHAPMAN, A.B., DICKERSON, G.E. 1949. Growth and production of inbred and outbred HolsteinFriesian cattle. J. Dairy Sci., 32:247-256.

WRIGHT, S. 1923. Mendelian analysis of pure breeds of livestock. I- The measurement of inbreeding and relationship. J. Heredity, 14:339-348.

YOUNG, C.W. 1984. Inbreeding and the gene pool. J. Dairy Sci., 67(2):472-477.

YOUNG, C.W., TYLER, W.J., FREEMAN, A.E., et al. 1969. Inbreeding investigations with dairy cattle in the North Central region of the United States. Minnesota Agric. Exp. Stn./ University of Minnesota. p.3-15 (Tech. Bull., 266).

Recebido em: 03/08/99

Aceito em: 14/08/00 